\title{
Effect of Chronic DL-Amphetamine Exposure on Brain Volume, Anxiogenic, Locomotor, and Social Behaviors in Male SD Rats
}

\author{
Alison F. Kafka, Daniel A. Heinz, Timothy M. Flemming, Paul J. Currie* \\ Department of Psychology, Reed College, Portland, USA \\ Email: "pcurrie@reed.edu
}

Received 9 June 2014; revised 24 July 2014; accepted 5 August 2014

Copyright (C) 2014 by authors and Scientific Research Publishing Inc.

This work is licensed under the Creative Commons Attribution International License (CC BY). http://creativecommons.org/licenses/by/4.0/

c) (i) Open Access

\section{Abstract}

Research examining the long-term effects of drugs such as Adderall ${ }^{\mathrm{TM}}$, a mixed DL-amphetamine, as a first-line treatment strategy for those diagnosed with attention deficit hyperactivity disorder (ADHD), is very much lacking. In order to address this, the present study sought to examine possible behavioral and neuroanatomical effects of chronic oral exposure to DL-amphetamine administered at a relatively low dose to the developing male Sprague Dawley rat. Animals were administered a mixture of chocolate drink and DL-amphetamine at a dose of $1.6 \mathrm{mg} / \mathrm{kg}$ for 36 days, beginning at PD 24 and ending at PD 60. Anxiety, a potential side effect of stimulant treatment, was assessed using three paradigms: The open field test (OF), the social interaction test (SI), and the elevated plus maze (EPM). The OF and SI were conducted using repeated testing over the course of five weeks. Testing occurred immediately after drug administration on a given day. The EPM was used only once on the penultimate day of treatment, before the drug was administered. Following drug treatment on PD 60, brain-to-body weight ratios were obtained. Results indicated that there were no group differences in brain-to-body weight ratios nor were differences in locomotor and social behaviors observed. However, rats treated with DL-amphetamine did show an anxiogenic response in the EPM. This was represented as a significant reduction in open arm entries. Overall our findings suggest that while chronic drug treatment fails to alter multiple measures of behavior, or reliable changes in brain volume, such treatment may impact a behavioral index of anxiety. Future research should seek to examine the implications of this heightened anxiogenic response in animals treated chronically with oral, low-dose DL-amphetamine.

\section{Keywords}

DL-Amphetamine, Brain, Elevated Plus Maze, Open Field, Psychostimulant, Social Interaction

\footnotetext{
"Corresponding author.
}

How to cite this paper: Kafka, A.F., Heinz, D.A., Flemming, T.M. and Currie, P.J. (2014) Effect of Chronic DL-Amphetamine Exposure on Brain Volume, Anxiogenic, Locomotor, and Social Behaviors in Male SD Rats. Journal of Behavioral and Brain Science, 4, 375-383. http://dx.doi.org/10.4236/jbbs.2014.48036 


\section{Introduction}

Adderall, a psychostimulant consisting of a mixture of dextroamphetamine and levoamphetamine, is considered the first line treatment strategy in response to a diagnosis of attention deficit hyperactivity disorder (ADHD) [1]. Psychostimulants, including DL-amphetamine and methylphenidate, are the most frequently prescribed psychiatric drugs within pediatric populations in the United States [2] [3]. ADHD is a pervasive behavioral disorder beginning in childhood, characterized by increased levels of inattention, hyperactivity, and impulsivity [4]. Worldwide, 5\% - 12\% of children are estimated to suffer from ADHD [5] [6], and estimates in North America range from $11 \%$ to $16 \%$ [7]-[9]. As of 2005, one in 20 to 25 North American children were prescribed some form of psychostimulant for the treatment of ADHD [10]. DL-amphetamine acts similarly to many drugs of abuse by competing with dopamine for a common binding site, the dopamine transporter (DAT), thereby allowing dopamine to accumulate in the synapse and extracellular space [11]. There is a distinct lack of research regarding possible effects of chronic exposure to DL-amphetamine during development. As ADHD is developmentally pervasive, and subsequent long-term maintenance treatment with psychostimulants is expected, research into the long-term behavioral and neuroanatomical effects of chronic DL-amphetamine is clearly necessary.

Most stimulant trials have been conducted using designs featuring acute administration to laboratory animals or adults in order to collect data regarding safety, dosing, and early efficacy [12]. Therefore, although DL-amphetamine administration may begin as young as Age 4, its effects on the developing brain are poorly understood [13]. The processes of overproduction of synaptic connections, pruning, and competitive elimination are especially active in the human brain between Ages 5 and 15 [14]-[16], a time at which ADHD treatment is prevalent. Common side effects of Adderall include nervousness and social withdrawal and the drug has been found to produce more severe adverse effects in comparison to methylphenidate, including negative affect and anxiety [17] [18]. Side effects that lend to its high abuse potential include pleasurable affect, elation, and euphoria [19] [20].

Acute, high doses of amphetamine and methamphetamine both produce neurotoxicity to dopaminergic neurons innervating the caudate putamen in rodents [21] [22]. However, only high acute doses have evidenced any neurotoxic effects in these animals [23]. In contrast, one study demonstrated significant reductions in striatal dopamine concentration and DAT density in adult baboons and squirrel monkeys after only four weeks of clinically relevant levels of mixed amphetamine administered twice daily [24]. Few studies, however, have thus far examined chronic, oral exposure to amphetamine at levels mimicking those that a human might receive throughout the developmental process. Therefore, in order to study the possibility of behavioral or neuroanatomical effects resulting from long-term, low-dose, oral treatment using DL-amphetamine at a course analogous to what may be expected for a child diagnosed with ADHD, the present study began administration at PD 24, at which time the rat brain is developmentally comparable to that of a seven-year-old human, and continued until PD 60, when brain markers demonstrate a parallel with human young adulthood around Age 21 [25]. Anxiety behaviors, as common side effects of amphetamine medication, were measured throughout development. Finally, in order to assess for neural developmental deficits, brain volume was measured on PD 60.

\section{Materials and Methods}

\subsection{Animals}

Male Sprague Dawley rats $(n=15)$ were housed in polypropylene cages, with free access to food and water. Animals were maintained in a temperature-controlled room $\left(22^{\circ} \mathrm{C}\right)$ and on a 12:12 hour light/dark cycle (lights off at 14:00). Rats were weaned at postnatal day (PD) 23, at which time they were housed 3 - 4 per cage. Body weights were measured weekly. All experiments were conducted in accordance with the Institutional Animals Care and Use Committee guidelines of Reed College.

\subsection{Drug and Administration Procedure}

DL-amphetamine hydrochloride (Sigma) was administered in a palatable liquid chocolate diet (Kellogg's Special K breakfast shake containing, per $296 \mathrm{ml}$, carbohydrate (18 g), fat (5 g), protein (10 g) and fibre (5 g)). Rats were trained to ingest the diet orally through a needleless syringe between PD 18 and PD 23. They typically learned to do so within one day, and ingested the mixture within 30 seconds. At PD 24, the 8 rats in the treat- 
ment group began drug administration at $1.6 \mathrm{mg} / \mathrm{kg} / \mathrm{ml}$. This protocol has been used successfully in previous literature [26] [27]. Administration continued daily for 36 days, until PD 60. Control animals $(n=7)$ received the liquid chocolate vehicle alone.

\subsection{Experimental Design}

Three experimental paradigms were employed and behaviors were digitally recorded. The effects of chronic DL-amphetamine on behavior in the open field and social interaction paradigms were investigated once per week over five weeks. Rats were tested in the EPM only once, on the day prior to the last day of drug administration. Measurements were carried out as described below. Animals were handled and habituated to the test room for one week prior to the beginning of testing. On each day of testing, rats were brought to the experimentation room at the beginning of the dark cycle and drug treatment was administered. Behavioral testing began within 45 minutes of drug administration. Each test apparatus was cleaned between subjects.

\subsubsection{Social Interaction (SI)}

Animals were paired with a novel partner who maintained a body weight within 15 grams of the subject's body weight, thereby minimizing dominance effects. The same partner was used for every subject within a given session. Testing was conducted in a polypropylene cage physically identical to the ones in which subjects were housed. Behavior was observed for 5 minutes using continuous focal sampling in order to quantify the amount of time spent engaging in social interaction. Relevant social interaction was defined as behavior initiated by the subject, such as grooming, sniffing, or following the partner [28].

\subsubsection{Open Field (OF)}

The apparatus was constructed of an $80 \times 80 \mathrm{~cm}$ chamber, with walls $30 \mathrm{~cm}$ in height. The floor of the apparatus was divided into 16 square segments each $20 \times 20 \mathrm{~cm}$ in size. The centre of the apparatus was divided further into one square area of $20 \times 20 \mathrm{~cm}$. This centre region was further subdivided into 4 equal centre squares. Animals were placed onto the centre segment of the apparatus. Behavior was measured using continuous focal sampling. Exploratory behavior was measured for 5 minutes. Dependent variables included time spent in the specific regions of the apparatus (centre or peripheral), frequency of rearing behaviors, and the number of lines crossed [29].

\subsubsection{Elevated Plus Maze (EPM)}

The EPM (MED Associates), a four arm apparatus standing $50 \mathrm{~cm}$ from the ground, consisted of two closed arms, surrounded by walls projecting $40 \mathrm{~cm}$ from the maze's floor, and two unwalled open arms, exposed to the external environment. A $10 \times 10 \mathrm{~cm}$ central square connected the four arms, forming the shape of a plus. A digital camera was mounted over the maze in order to record the movement of the rat using video tracking software (Version 1.14, MED Associates). Rats were placed within the central area of the EPM and open and closed arm exploratory behaviors were digitally recorded for 5 minutes as described previously [30]. Animals were tested on PD 59.

\subsection{Brain Volume}

On PD 60, all animals were euthanized via $\mathrm{CO}_{2}$ inhalation and then decapitated. Brains were extracted and immediately weighed in order to obtain brain-to-body weight ratios.

\subsection{Statistical Analyses}

Two-way (drug $\times$ time) analysis of variance (ANOVA) and independent t-tests were used in order to analyze differences in behavioral measures and in brain volumes between treatment and control conditions. All analyses were conducted using STATISTICA (StatSoft).

\section{Results}

The SI test quantified the amount of time each test subject spent engaged with a novel conspecific rat. While social interaction was generally higher in the first two weeks of testing $(F(2,4)=188.48, p<0.0001)$, possibly re- 
flecting enhanced activity and curiosity at this stage of development, a two-way (drug $\times$ time) ANOVA, with repeated measures on the latter variable, did not reveal any significant group differences across weeks $(F(4,52)=$ 0.60 , p > 0.05) (See Figure 1). Similarly, ANOVA did not indicate reliable differences between drug and vehicle-treated animals in OF testing. No differences in exploratory behavior were observed using ratios of the time spent in the centre versus time spent in the periphery of the apparatus $(F(4,52)=1.14, p>0.05$; Figure 2). Group differences were also not found in rearing behavior $(F(4,52)=0.82, p>0.05$; Figure 3$)$ or in the number of lines crossed $(F(4,52)=1.03$, p > 0.05; Figure 4). In contrast, we did observe group differences in the EPM paradigm. Rats treated with DL-amphetamine exhibited an increased avoidance of the open arms compared to

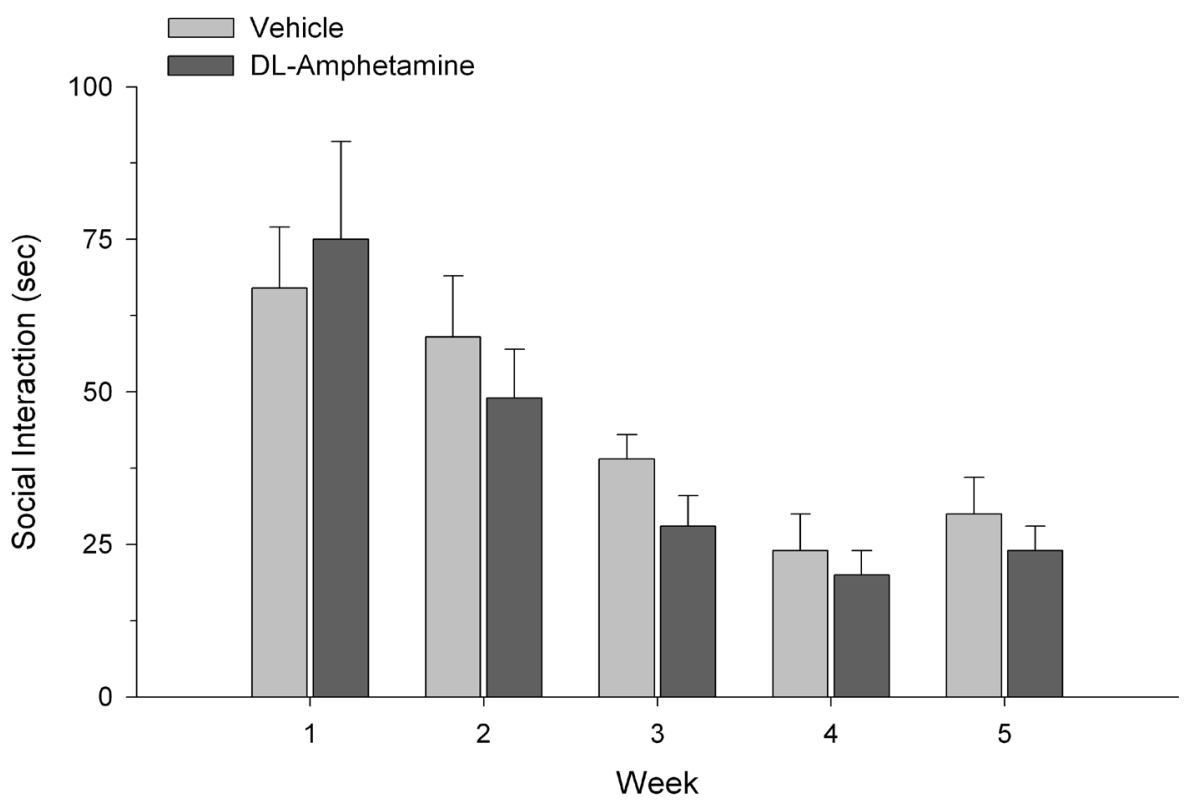

Figure 1. Effect of DL-amphetamine administration on social interaction behavior measured over five weeks. Values represent mean \pm S.E.M. While SI scores were higher in both groups during the first two weeks of treatment, no drug effect, or interaction, was observed.

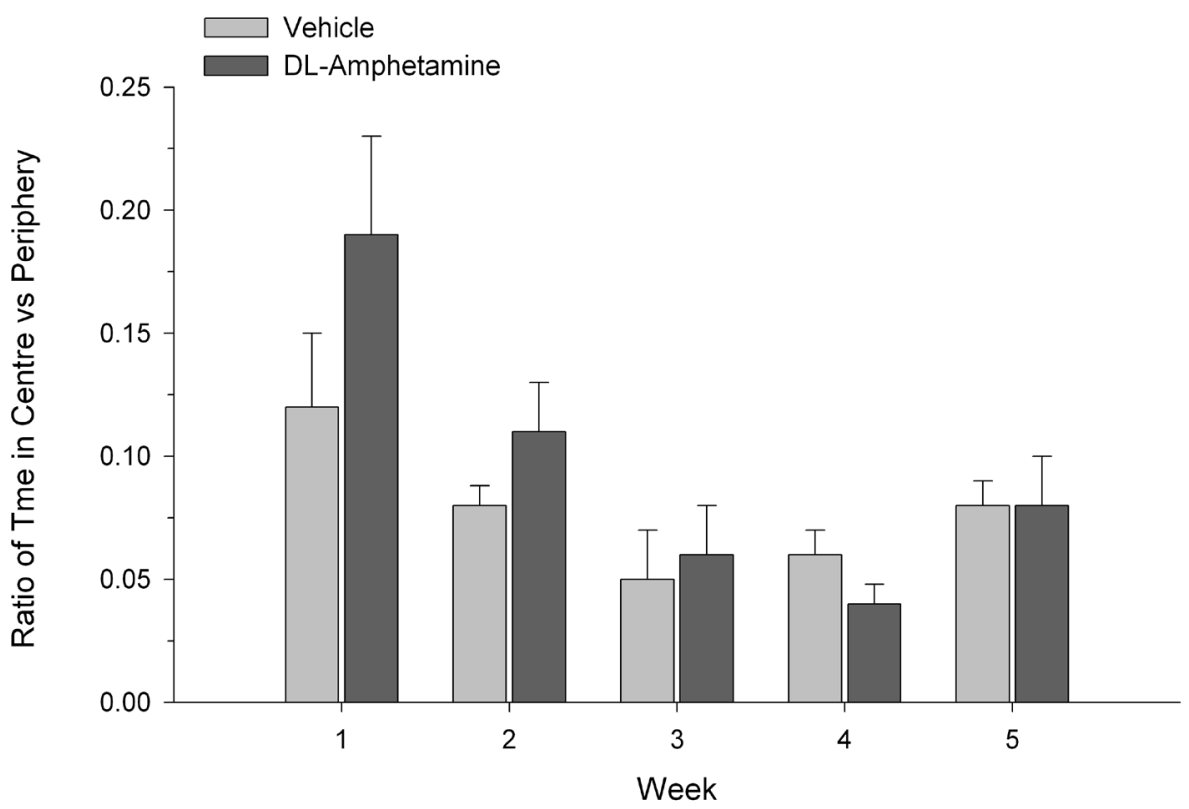

Figure 2. Ratio of time spent in the centre versus periphery of open field apparatus. Data are presented as mean \pm S.E.M. 


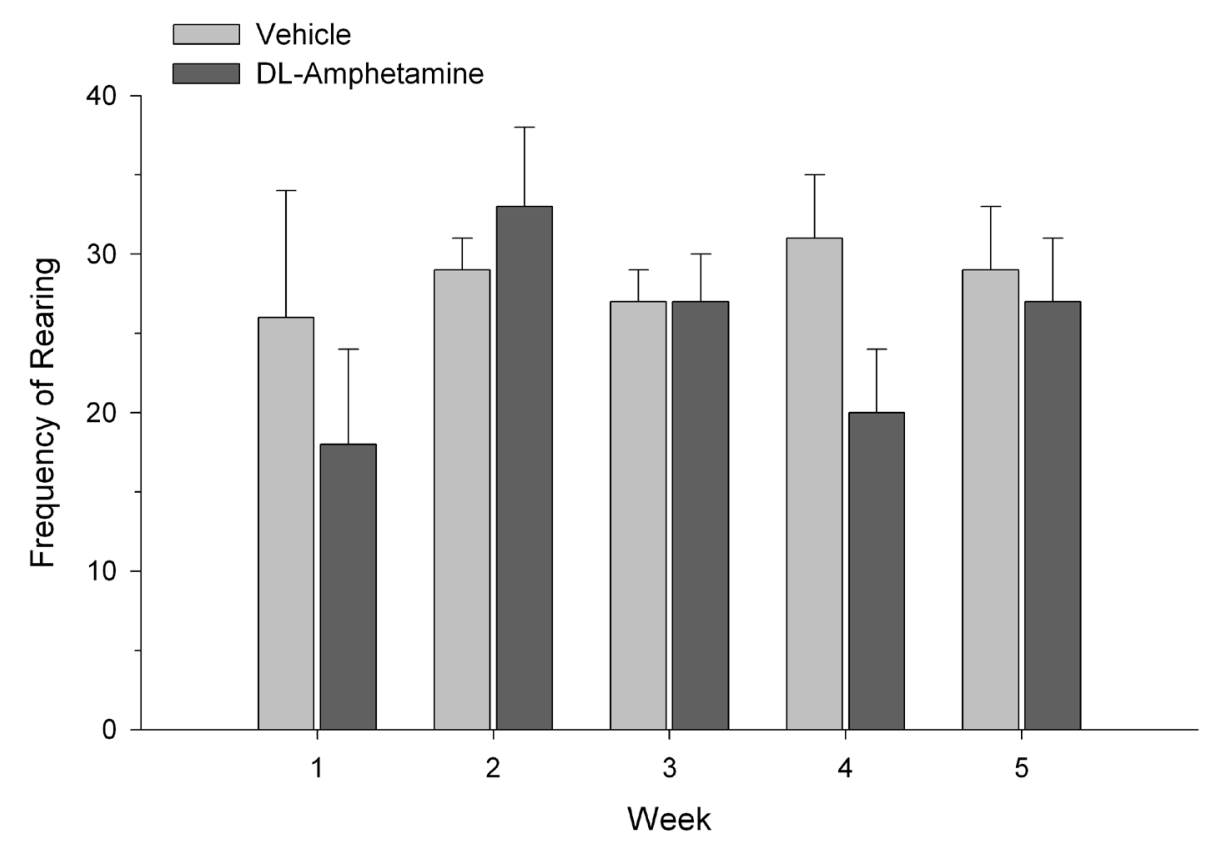

Figure 3. Frequency of rearing behavior in vehicle and DL-amphetamine-treated rats. Data are represented as mean \pm S.E.M.

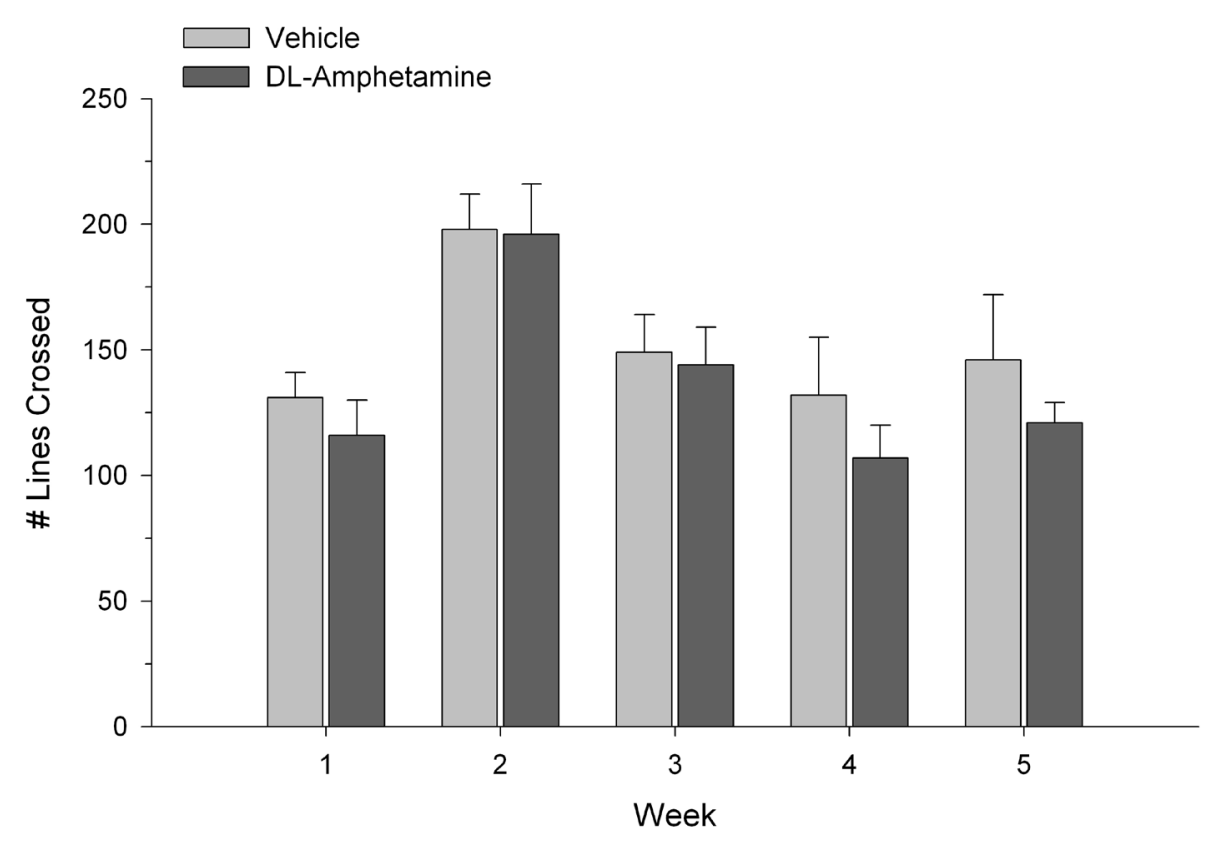

Figure 4. Locomotor activity in open field testing. Values represent mean \pm S.E.M. lines crossed.

vehicle control. This was reflected in a reduced number of open arm entries $(t(13)=2.33, p=0.04$; Figure 5). Finally, there were no groups differences in brain-to-body weight ratios, $t(13)=1.44, \mathrm{p}>0.05$; Figure 6 ).

\section{Discussion}

Few studies to date have examined the effect of long-term psychostimulant exposure in developing animal models. In the present study we investigated the impact of chronic DL-amphetamine administration in young male Sprague Dawley rats. In open field and social interaction testing, as well as measurements of brain-to-body 


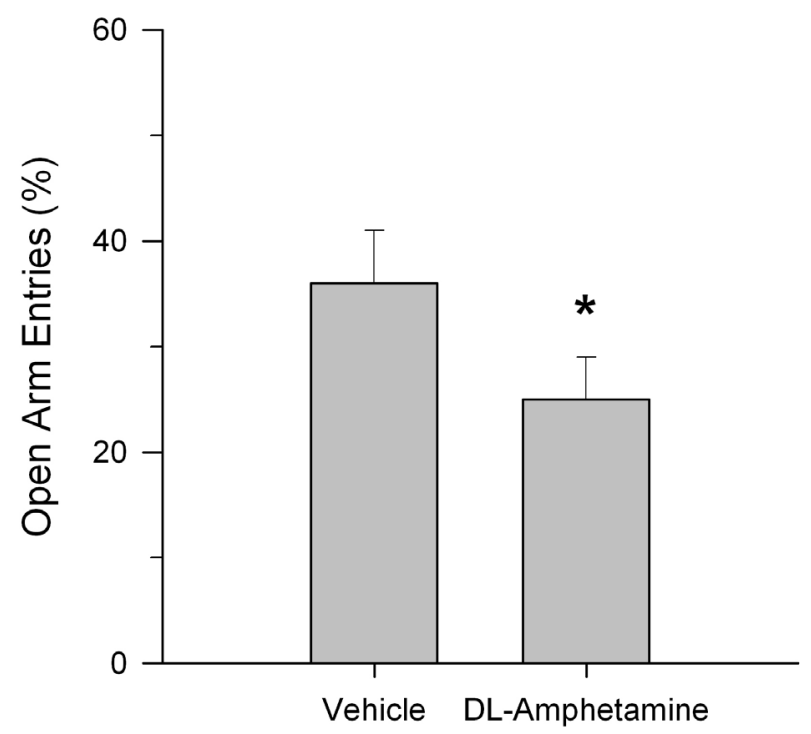

Figure 5. Percent open arm entries in the elevated plus maze in vehicle and drug-treated rats. Testing was conducted on PD 59. Data are presented as mean \pm S.E.M. open arm entries. Rats treated with DL-amphetamine exhibited an increased avoidance of the open arms. ${ }^{*} \mathrm{p}<0.05$ compared to control.

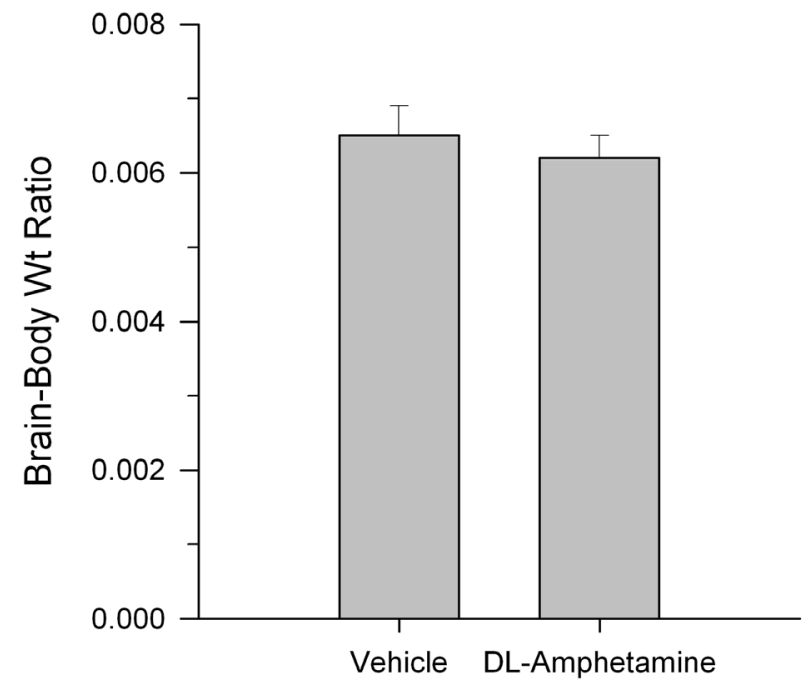

Figure 6. Mean \pm S.E.M. brain-to-body weight ratios in rats following five weeks of vehicle or DL-amphetamine administration. No group differences were observed.

weight ratios, we observed no reliable differences between treatment and control conditions. This suggests a lack of effect of drug treatment on exploratory and social behaviors and also indicates that chronic low dose exposure may not elicit changes in overall brain volume.

However, when examined in the EPM, rats treated daily with DL-amphetamine did exhibit significantly fewer entries into the open arms, consistent with the induction of anxiogenic behavior. Our observed increase in anxiogenesis is in fact consistent with previous work suggesting that such treatment may evoke negative affect and anxiety in humans [17] [18] [31]. However, given that we tested rats in the EPM prior to drug treatment on PD 59, one could argue that the observed impact on EPM behavior might be attributed, at least in part, to drug withdrawal and/or reduced drug availability. In order to rule out this possibility, rats would need to be tested in the EPM immediately after drug administration. If, under such conditions, animals continued to show reduced 
EPM open arm exploration, such a hypothesis would be called into question.

The lack of statistical differences in brain-to-body weight ratios suggest that widespread neuroanatomical alterations may not result from chronic treatment with low-dose DL-amphetamine. However, due to potential species differences in pharmacokinetic and pharmacodynamics properties of central nervous system (CNS) stimulants, caution in interpretation may be warranted [23]. As described above, 30\% - 50\% decreases in striatal dopamine concentrations and DAT density in baboons and squirrel monkeys have been observed following four weeks of oral, low-dose mixed amphetamine treatment [24]. Similarly, Melega et al. [32] found that two injections of $2 \mathrm{mg} / \mathrm{kg}$ of amphetamine to vervet monkeys resulted in an almost $90 \%$ decrease in caudate nucleus dopamine concentrations. While daily administration of $2.5 \mathrm{mg} / \mathrm{kg}$ amphetamine fails to produce such an effect in the caudate putamen of rats, higher doses may effectively reduce levels of the catecholamine [33] and, moreover, the dose effect may differ in acute drug administration paradigms [34] [35].

In humans, stimulant treatment has been observed to elicit decreases in body weight. For example, Swanson et al. [36] have reported a decrease in weight by $2.7 \mathrm{~kg}$ in children. However, in our experiment we did not detect alterations in rat body weights after chronic low dose drug exposure. Further, while we did not observe any changes in overall brain volume, we cannot argue against potential differences within specific brain regions or synapses. In fact recent work has demonstrated that ventral tegmental area neuronal activity correlates with the animal's behavioral response to chronic methylphenidate treatment [37], a brain region implicated in drug reward and reinforcement [38] [39]. Whether or not chronic low dose DL-amphetamine treatment also leads to specific changes in limbic structures controlling emotional behavior remains to be determined. Such changes might very well underlie the increase in anxiogenic behavior observed here.

\section{Conclusion}

In the present report we investigated the behavioral and neuroanatomical impact of chronic oral exposure to a low dose of DL-amphetamine administered to adolescent male Sprague Dawley rats. While we observed no group differences in brain-to-body weight ratios or differences in locomotor or social behaviors, rats treated with DL-amphetamine did exhibit anxiogenic behavior when tested in the EPM. Future research should be directed at examining the implications of this heightened anxiogenic response in animals treated chronically with oral, low-dose DL-amphetamine.

\section{Acknowledgements}

Supported by the Murdock Charitable Trust—Life Sciences to PJC.

\section{References}

[1] Hodgkins, P., Shaw, M., McCarthy, S. and Sallee, F.R. (2012) The Pharmacology and Clinical Outcomes of Amphetamines to Treat ADHD: Does Composition Matter? CNS Drugs, 26, 245-268. http://dx.doi.org/10.2165/11599630-000000000-00000

[2] Hisle-Gorman, E., Eide, M., Coll, E.J. and Gorman, G.H. (2014) Attention Deficit Hyperactivity Disorder and Medication Use by Children During Parental Military Deployments. Military Medicine, 179, 573-578. http://dx.doi.org/10.7205/MILMED-D-13-00334

[3] Wolraich, M.L. (1999) Attention Deficit Hyperactivity Disorder: The Most Studied and Yet the Most Controversial Diagnosis. Mental Retardation and Developmental Disabilities Research Reviews, 5, 163-1688.

[4] American Psychiatric Association (2013) Neurodevelopmental Disorders (5th Edition). The Diagnostic and Statistical Manual of Mental Disorders, 59-66. http://dx.doi.org/10.1176/appi.books.9780890425596.514988

[5] Polanczyk, G. and Rohde, L.A. (2007) Epidemiology of Attention-Deficit/Hyperactivity Disorder across the Lifespan. Current Opinion in Psychiatry, 20, 386-392. http://dx.doi.org/10.1097/YCO.0b013e3281568d7a

[6] Faraone, S.V. and Biederman, J. (2005) What Is the Prevalence of Adult ADHD? Results of a Population Screen of 966 Adults. Journal of Attention Disorders, 9, 384-391. http://dx.doi.org/10.1177/1087054705281478

[7] Visser, S.M., Danielson, M.L., Bitsko, R.H., Holbrook, J.R., Kogan, M.D., Ghandour, R.M., Perou, R. and Blumberg, S.J. (2014) Trends in the Parent Report of Healthcare Provider-Diagnosed and Medicated Attention-Deficit/Hyperactivity Disorder: United States, 2003-2011. Journal of the American Academy of Child and Adolescent Psychiatry, 53, 34-46. http://dx.doi.org/10.1016/j.jaac.2013.09.001

[8] Rowland, A.S., Umbach, D.M., Catoe, K.E., Stallone, L., Long, S., Rabiner, D., Naftel, A.J., Panke, D., Faulk, R. and 
Sandler, D.P. (2001) Studying the Epidemiology of Attention-Deficit Hyperactivity Disorder: Screening Method and Pilot Results. Canadian Journal of Psychiatry, 46, 931-940.

[9] Price, J.H., Khubchandani, J., McKinney, M. and Braun, R. (2013) Racial/Ethnic Disparities in Chronic Diseases of Youths and Access to Health Care in the United States. BioMed Research International, 2013, Article ID: 787616. http://dx.doi.org/10.1155/2013/787616

[10] Zuvekas, S., Vitiello, B. and Norquist, G. (2006) Recent Trends in Stimulant Medication Use Among US Children. The American Journal of Psychiatry, 163, 579-585. http://dx.doi.org/10.1176/appi.ajp.163.4.579

[11] Fleckenstein, A.E., Volz, T.J., Riddle, E.L., Gibb, J.W. and Hanson, G.R. (2007) New Insights into the Mechanism of Action of Amphetamines. Annual Review of Pharmacology and Toxicology, 47, 681-698. http://dx.doi.org/10.1146/annurev.pharmtox.47.120505.105140

[12] Aagaard, L. and Hansen, E.H. (2011) The Occurrence of Adverse Drug Reactions Reported for Attention Deficit Hyperactivity Disorder (ADHD) Medications in the Pediatric Population: A Qualitative Review of Empirical Studies. Neuropsychiatric Disease and Treatment, 7, 729-744. http://dx.doi.org/10.2147/NDT.S26403

[13] Zito, J.M., Safer, D.J., dos Reis, S., Gardner, J.F., Boles, M. and Lynch, F. (2000) Trends in the Prescribing of Psychotropic Medications to Preschoolers. The Journal of the American Medical Association, 283, 1025-1030. http://dx.doi.org/10.1001/jama.283.8.1025

[14] Andersen, S.L. and Teicher, M.H. (2000) Sex Differences in Dopamine Receptors and Their Relevance to ADHD. Neuroscience \& Biobehavioral Reviews, 24, 137-141. http://dx.doi.org/10.1016/S0149-7634(99)00044-5

[15] Brenhouse, H.C. and Andersen, S.L. (2011) Developmental Trajectories during Adolescence in Males and Females: A Cross-Species Understanding of Underlying Brain Changes. Neuroscience \& Biobehavioral Reviews, 35, 1687-1703. http://dx.doi.org/10.1016/j.neubiorev.2011.04.013

[16] Rakic, P., Bourgeois, J.P., Eckenhoff, M.F., Zecevic, N. and Goldman-Rakic, P.S. (1986) Concurrent Overproduction of Synapses in Diverse Regions of the Primate Cerebral Cortex. Science, 232, 232-235. http://dx.doi.org/10.1126/science.3952506

[17] Efron, D., Jarman, F. and Barker, M. (1997) Side Effects of Methylphenidate and Dexamphetamine in Children with Attention Deficit Hyperactivity Disorder: A Double-Blind, Crossover Trial. Pediatrics, 100, 662-666. http://dx.doi.org/10.1542/peds.100.4.662

[18] Pliszka, S.R., Browne, R.G., Olvera, R.L. and Wynne, S.K. (2000) A Double-Blind, Placebo-Controlled Study of Adderall and Methylphenidate in the Treatment of Attention-Deficit/Hyperactivity Disorder. Journal of the American Academy of Child \& Adolescent Psychiatry, 39, 619-626. http://dx.doi.org/10.1097/00004583-200005000-00016

[19] Ahmann, P.A., Theye, F.W., Berg, R., Linquist, A.J., Van Erem, A.J. and Campbell, L.R. (2001) Placebo-Controlled Evaluation of Amphetamine Mixture-Dextroamphetamine Salts and Amphetamine Salts (Adderall): Efficacy Rate and Side Effects. Pediatrics, 107, e10-e10. http://dx.doi.org/10.1542/peds.107.1.e10

[20] Lakhan, S.E. and Kirchgessner, A. (2012) Prescription Stimulants in Individuals with and without Attention Deficit Hyperactivity Disorder: Misuse, Cognitive Impact, and Adverse Effects. Brain and Behavior, 2, 661-677. http://dx.doi.org/10.1002/brb3.78

[21] Clausing, P., Gough, B., Holson, R.R., Slikker, W. and Bowyer, J.F. (1995) Amphetamine Levels in Brain Microdialysate, Caudate/Putamen, Substantia Nigra and Plasma after Dosage That Produces Either Behavioral or Neurotoxic Effects. Journal of Pharmacology and Experimental Therapeutics, 274, 614-621.

[22] Kita, T., Asanuma, M., Miyazaki, I. and Takeshima, M. (2014) Protective Effects of Phytochemical Antioxidants against Neurotoxin-Induced Degeneration of Dopaminergic Neurons. Journal of Pharmacological Sciences, 124, 313319. http://dx.doi.org/10.1254/jphs.13R19CP

[23] Berman, S.M., Kuczenski, R., McCracken, J.T. and London, E.D. (2008) Potential Adverse Effects of Amphetamine Treatment on Brain and Behavior: A Review. Molecular Psychiatry, 14, 123-142. http://dx.doi.org/10.1038/mp.2008.90

[24] Ricaurte, G.A., Mechan, A.O., Yuan, J., Hatzidimitriou, G., Xie, T., Mayne, A.H. and McCann, U.D. (2005) Amphetamine Treatment Similar to That Used in the Treatment of Adult Attention-Deficit/Hyperactivity Disorder Damages Dopaminergic Nerve Endings in the Striatum of Adult Nonhuman Primates. Journal of Pharmacology and Experimental Therapeutics, 315, 91-98. http://dx.doi.org/10.1124/jpet.105.087916

[25] Andersen, S.L. (2003) Trajectories of Brain Development: Point of Vulnerability or Window of Opportunity? Neuroscience \& Biobehavioral Reviews, 27, 3-18. http://dx.doi.org/10.1016/S0149-7634(03)00005-8

[26] Allen, J.K., Wilkinson, M., Soo, E.C., Hui, J.P.M., Chase, T.D. and Carrey, N. (2010) Chronic Low Dose Adderall $\mathrm{XR}^{\circledR}$ Down-Regulates cfos Expression in Infantile and Prepubertal Rat Striatum and Cortex. Neuroscience, 169, 19011912. http://dx.doi.org/10.1016/j.neuroscience.2010.06.029

[27] Chase, T.D., Carrey, N., Soo, E. and Wilkinson, M. (2007) Methylphenidate Regulates Activity Regulated Cytoskeletal 
Associated but Not Brain-Derived Neurotrophic Factor Gene Expression in the Developing Rat Striatum. Neuroscience, 144, 969-984. http://dx.doi.org/10.1016/j.neuroscience.2006.10.035

[28] Ramos, A., Homem, K.S.D.C., Suchecki, D., Tufik, S. and Troncone, L.RP. (2014) Drug-Induced Suppression of ACTH Secretion Does Not Promote Anti-Depressive or Anxiolytic Effects. Behavioural Brain Research, 265, 69-75. http://dx.doi.org/10.1016/j.bbr.2014.02.024

[29] Rainer, Q., Speziali, S., Rubino, T., Dominguez-Lopez, S., Bambico, F.R., Gobbi, G. and Parolaro, D. (2014) Chronic Nandrolone Decanoate Exposure during Adolescence Affects Emotional Behavior and Monoaminergic Neurotransmission in Adulthood. Neuropharmacology, 83, 79-88. http://dx.doi.org/10.1016/j.neuropharm.2014.03.015

[30] Currie, P.J., Schuette, L.M., Wauson, S.E., Voss, W.N. and Angeles, M.J. (2014) Activation of Urocortin 1 and Ghrelin Signaling in the Basolateral Amygdala Induces Anxiogenesis. NeuroReport, 25, 60-64.

[31] Narine, C., Sarwar, S.R. and Rais, T.B. (2013) Adderall-Induced Trichotillomania: A Case Report. Innovations in Clinical Neuroscience, 10, 13.

[32] Melega, W.P., Raleigh, M.J., Stout, D.B., Lacan, G., Huang, S.C. and Phelps, M.E. (1997) Recovery of Striatal Dopamine Function after Acute Amphetamine- and Methamphetamine-Induced Neurotoxicity in the Vervet Monkey. Brain Research, 766, 113-120. http://dx.doi.org/10.1016/S0006-8993(97)00548-9

[33] Segal, D.S. and Kuczenski, R. (1997) Repeated Binge Exposures to Amphetamine and Methamphetamine: Behavioral and Neurochemical Characterization. Journal of Pharmacology and Experimental Therapeutics, 282, 561-573.

[34] Jedema, H.P., Narendran, R. and Bradberry, C.W. (2014) Amphetamine-Induced Release of Dopamine in Primate Prefrontal Cortex and Striatum: Striking Differences in Magnitude and Timecourse. Journal of Neurochemistry, Early View. http://dx.doi.org/10.1111/jnc.12743

[35] Ren, J., Xu, H., Choi, J.K., Jenkins, B.G. and Chen, Y. (2009) Dopaminergic Response to Graded Dopamine Concentration Elicited by Four Amphetamine Doses. Synapse, 63, 764-772. http://dx.doi.org/10.1002/syn.20659

[36] Swanson, J.M., Elliott, G.R., Greenhill, L.L., Wigal, T., Arnold, L.E., Vitiello, B., et al. (2007) Effects of Stimulant Medication on Growth Rates across 3 Years in the MTA Follow-Up. Journal of the American Academy of Child \& Adolescent Psychiatry, 46, 1015-1027. http://dx.doi.org/10.1097/chi.0b013e3180686d7e

[37] Jones, Z., Vazquez, C.R. and Dafny, N. (2014) Ventral Tegmental Area Neuronal Activity Correlates to Animals’ Behavioral Response to Chronic Methylphenidate Recorded from Adolescent SD Male Rats. Journal of Behavioral and Brain Science, 4, 168-189. http://dx.doi.org/10.4236/jbbs.2014.44020

[38] Cepko, L.C.S., Selva, J.A., Merfeld, E.B., Fimmel, A.I., Goldberg, S.A. and Currie, P.J. (2014) Ghrelin Alters the Stimulatory Effect of Cocaine on Ethanol Intake Following Mesolimbic or Systemic Administration. Neuropharmacology, 85, 224-231. http://dx.doi.org/10.1016/j.neuropharm.2014.05.030

[39] Schuette, L.M., Gray, C.C. and Currie, P.J. (2013) Microinjection of Ghrelin into the Ventral Tegmental Area Potentiates Cocaine-Induced Conditioned Place Preference. Journal of Behavioral and Brain Science, 3, 576-580. http://dx.doi.org/10.4236/jbbs.2013.38060 
Scientific Research Publishing (SCIRP) is one of the largest Open Access journal publishers. It is currently publishing more than 200 open access, online, peer-reviewed journals covering a wide range of academic disciplines. SCIRP serves the worldwide academic communities and contributes to the progress and application of science with its publication.

Other selected journals from SCIRP are listed as below. Submit your manuscript to us via either submit@scirp.org or Online Submission Portal.
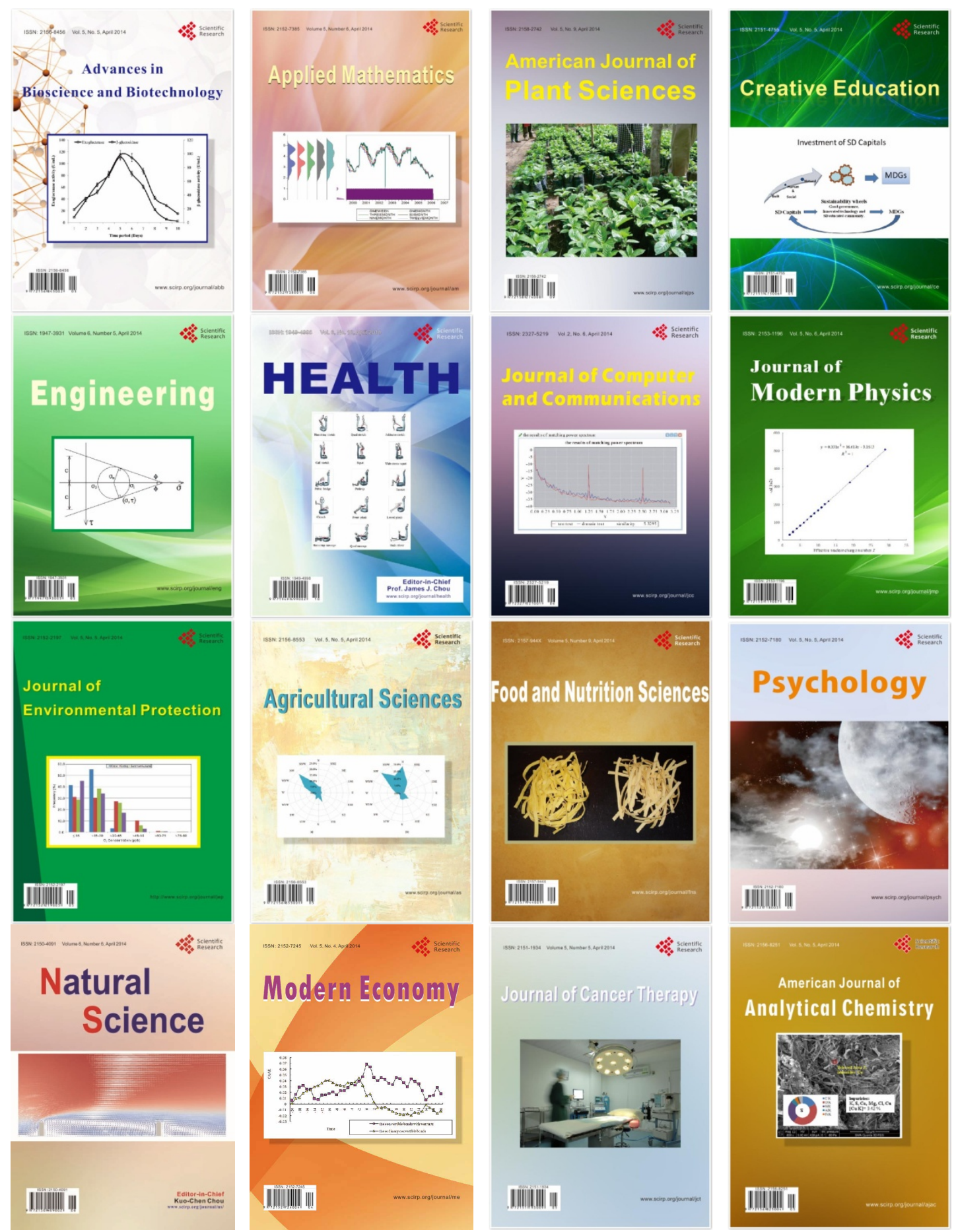